\section{Locación de inmuebles: la Ley 27.551 y su relación con la normativa de emergencia}

\author{
Property lease: Law 27.551 and its connection \\ with the emergency legislation
}

\section{Federico Manuel Lértora}

\section{RESUMEN}

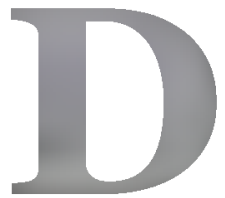

esde el 1 de julio de 2020, se encuentra vigente en nuestro país la Ley 27.551, que ha efectuado modificaciones al Código Civil y Comercial de la Nación Argentina, fundamentalmente en relación al contrato de locación de inmuebles y en particular respecto de la locación de inmuebles con destino a vivienda. La ley se divide en cuatro títulos, correspondiéndose cada uno de ellos, a las modificaciones al Código, al dictado de normativa complementaria, a la creación del programa nacional de alquiler social y al fomento de medios alternativos de resolución de conflictos, respectivamente, reafirmando una naturaleza tuitiva en miras a la protección del locatario. Este trabajo profundizará sobre los primeros dos títulos, recabando opiniones de distintos juristas al respecto. Asimismo, analizará la relación entre la Ley 27.551 y la normativa de emergencia dictada producto de la Pandemia (Covid-19) en materia de locaciones, en razón del llamado diálogo de fuentes.

Palabras clave: locación de inmuebles; reforma al Código Civil y Comercial de la Nación Argentina; normativa de emergencia.

\section{ABSTRACT}

Since July 1st., 2020, Law 27.551 entered into effectiveness in our country, changing the Civil and Commercial Code mainly regarding the property lease contract and in particular regarding the property with residence purposes lease. The legislation is divided into four headings, each of them corresponding to the modifications of the Code, the passing of complementary normative, the creation of the National Program of social 'rent', and the promotion of alternative means of conflict resolutions, respectively, reaffirming a protective nature in sights of the protection of the lessee. This paper will focus on the first
Federico Manuel Lértora federicolertora@hotmail.com

Facultad de Ciencias Económicas

Universidad Nacional del Nordeste ARGENTINA

COMO CITAR ESTE ARTÍCULO Lértora, F. M. (2020). Locación de inmuebles: la Ley 27.551 y su relación con la normativa de emergencia. Revista de la Facultad de Ciencias Económicas, 23(2), 155 - 171.

http://dx.doi.org/10.30972/rfce.2524570

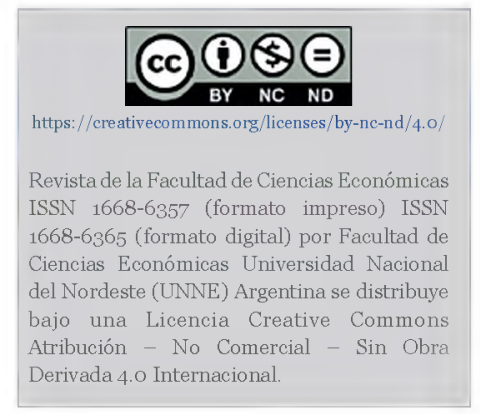


two headings, gathering different jurists' opinions in that regard. Additionally, it will analyze the connection between Law 27.551 and the emergency legislation passed as a result of de Covid-19 pandemic regarding leases, on the grounds of the so called "sources dialogue".

Keywords: property lease; Civil and Commercial Codereform Argentinian; emergency legislation.

\section{INTRODUCCIÓN}

En el Código Civil y Comercial de la Nación Argentina (en adelante CCC) el contrato de locación se encuentra regulado en el capítulo 4 del Título IV (Contratos en particular), que integra a su vez el Libro Tercero, referente a los Derechos Personales. Este cuerpo normativo modifica el criterio del Código Civil derogado, regulando el contrato de locación de cosas como un contrato distinto al de obra y al de servicios (Di Chiazza, 2016).

Asimismo, con la aprobación del CCC se deroga expresamente la Ley 23.091, Ley de Locaciones Urbanas, manteniéndose vigente sin embargo la Ley 13.245, de Arrendamiento de Inmuebles Rurales.

Antes de sumergirnos en el análisis de la Ley 27.551, de reforma al Código Civil y Comercial de la Nación en temas referidos al contrato de locación, resulta importante recordar que en materia contractual rige el principio de autonomía de la voluntad y libertad de contratación; esto es, que las partes son libres para celebrar un contrato y determinar su contenido, dentro de los límites impuestos por la ley, el orden público, la moral y las buenas costumbres, y que las normas legales relativas a los contratos son supletorias de la voluntad de las partes, siendo esto de plena aplicación en contratos paritarios o negociados.

Sin embargo, al analizar el CCC sostienen Hernández y Frustagli (2017) que, en lo que respecta a la locación existe una modernización legislativa, apuntando principalmente a redefinir el orden público de protección, que atiende al resguardo de la vivienda familiar y de tutela de los intereses de los débiles jurídicos.

Borda (2018), en igual sentido, manifiesta que hay una notoria tendencia legislativa a proteger al locatario en desmedro del dueño, acentuándose esto con motivo de la escasez de vivienda originada en procesos económicos como ser el encarecimiento de la construcción y el éxodo de la población del campo a las ciudades.

Coincidentemente, agregan los ya citados Hernández y Frustagli, que el ordenamiento jurídico (CCC) se avoca generalmente a la búsqueda de la protección del locatario, pudiendo aplicarse con frecuencia en este ámbito el régimen de defensa del consumidor, entendiendo que el vínculo entre el locador profesional y el locatario habitacional constituye una típica relación de consumo. 
Acentuando la concepción tuitiva, a partir del del 1 de julio de 2020 se encuentra vigente en nuestro país la Ley 27.551, que ha efectuado modificaciones al CCC, fundamentalmente en relación al contrato de locación de inmuebles. Si bien la ley cuenta solamente con 24 artículos, busca lograr un cambio importante en este tipo contractual, especialmente en referencia a la locación de cosas inmuebles con destino a vivienda, intentando darle a esta especie un tratamiento singular, caracterizado por un reparto de derechos y obligaciones que tiende a generar mayores fortalezas al contratante locatario o inquilino (Ayala, 2020).

Entre los fundamentos del proyecto que dio origen a la normativa de referencia puede leerse que "si bien el Código Civil y Comercial de la Nación regula las cuestiones concermientes al contrato de locación, en particular los aspectos relacionados con la locación habitacional, la protección brindada resulta exigua en relación a las exigencias del tráfico jurídico actual y las necesidades generadas por la situación de debilidad y vulnerabilidad en la que se encuentran incursos determinados locatarios, siendo entonces necesario prever ciertos asuntos que conlleven a una mayor claridad, seguridad y previsibilidad en las relaciones locativas".

\section{LA LEY 27.551}

Como ya fuera mencionado, el día 11 de junio del 2020 el congreso sancionó la Ley 27.551, bautizada por la opinión pública como la "Ley de Alquileres". Dicha normativa fue publicada en el Boletín Oficial de la República Argentina el día 30 de junio de 2020, entrando finalmente en vigencia a partir del $1^{\circ}$ de julio.

Este cuerpo normativo se compone de un total de veinticuatro artículos, los que a su vez están organizados en cuatro títulos. El primero de ellos se denomina "Reforma al Código Civil y Comercial de la Nación" y el segundo se titula "Regulación Complementaria de las Locaciones". Estos títulos serán el objeto de estudio del presente trabajo, no constituyendo el mismo un análisis acabado de los institutos que lo componen, sino un análisis descriptivo de la nueva normativa vigente, recalando las opiniones de distintos juristas al respecto.

Además, la ley se integra con el título III, que refiere al "Programa de Alquiler Social"creado por el artículo 17 de la misma ley, mientras que el título IV versa sobre "métodos alternativos de resolución de conflictos". Si bien, estos títulos no son el punto central del presente trabajo, efectuaremos una somera mención de su contenido.

${ }^{1}$ Recuperado de https://www.hcdn.gov.ar/proyectos/proyecto.jsp?exp=4316-D-2019 


\section{ANÁLISIS DE LA LEY}

\section{Las reformas al Código Civil y Comercial de la Nación}

Como hemos comentado, el título I agrupa las modificaciones al Código Civil y Comercial de la Nación sancionado en el año 2015. En tal sentido, "la nueva ley" reforma diez artículos de la redacción original $(75,1196,1198,1199,1201,1203,1209,1221,1222$ y 1351) e incorpora dos nuevos artículos bajo la numeración 1204 bis y 1221 bis, respectivamente.

A los fines de un mejor ordenamiento, abordaremos los artículos, en el orden de su inclusión en la ley.

\section{Artículo 1ㅇ: Artículo 75 CCC. Domicilio Especial}

El Código Civil y Comercial, dispone que las partes de un contrato pueden elegir un domicilio para el ejercicio de los derechos y obligaciones que de él emanan.

Si bien la Ley 27.551 no modificó este enunciado, incorporó la posibilidad de que las partes puedan, además, constituir un domicilio electrónico en el que se tengan por eficaces todas las notificaciones, comunicaciones y emplazamientos que a dicho domicilio se dirijan.

Afirman Hernández y Frustagli (2020) que la reforma continúa la tendencia del CCC, de abrirse al impacto de la tecnología; en este caso buscando beneficiar al locatario en la celeridad, seguridad y gratuidad a la hora de cursarle sus comunicaciones al locador.

Por su parte, Moroz (2020) entiende que existirían en la actualidad dos variantes de domicilio especial contractual; la primera de ellas, contenida en la primera parte del artículo 75 del código; esto es, el clásico domicilio físico/geográfico especial contractual, el que podrán elegir las partes de un contrato para el ejercicio de los derechos y obligaciones que de él emanan. La segunda de las posibilidades contempladas en la reforma, sería precisamente el domicilio especial electrónico contractual, que también podrán elegir las partes de un contrato para que se tengan por eficaces todas las notificaciones comunicaciones y emplazamientos allí dirigidos.

Agrega este autor, que el domicilio especial electrónico es una pura facultad o potestad de las partes, quienes en uso de su autonomía de la voluntad podrán pactarlo libremente si así desean hacerlo, siendo complementario del domicilio especial contractual "clásico".

Lo cierto es que la modificación implica una novedad respecto de las partes de un contrato, evitando alargar tiempos y generar otros costos (Pano \& Salgado, 2020). Esto no significa que no pueda suscitar controversias de las más variadas en la práctica. 


\section{Artículo 2 ${ }^{\circ}$ : Artículo 1196 CCC. Locación Habitacional}

Al igual que el artículo sustituido, el nuevo artículo 1196 del CCC establece que, si el destino del inmueble es habitacional no puede requerirse del locatario el pago de alquileres anticipados por periodos mayores a un mes.

El inciso b del artículo bajo análisis, en cambio, ha sufrido algunas modificaciones. En su origen disponía que, en las locaciones habitacionales no podía exigirse al locatario, depósitos de garantías o exigencias asimilables, por cantidad mayor del importe equivalente a un mes de alquiler por cada año de locación contratado. Por su parte, el nuevo inciso b, establece que los depósitos de garantía o exigencias asimilables, requeridas al locatario no podrán ser mayores al importe correspondiente al primes mes de alquiler.

Asimismo, agrega el inciso mencionado que el depósito de garantía será devuelto mediante la entrega de una suma equivalente al precio del último mes de la locación, o la parte proporcional en caso de haberse efectuado un depósito inferior a un mes de alquiler, debiendo hacer el reintegro efectivo en el momento de la restitución del inmueble por parte del locatario.

La modificación estipulada tiene por fin generar una devolución que es equitativa para ambas partes, ajustando el monto de la suma que se debe reintegrar al momento de la restitución del inmueble (Falcon, 2020).

En este sentido, se reconoce al depósito en garantía como una deuda de valor, siendo esta una variedad de las deudas pecuniarias que aparece cuando se prevé que el objeto de la obligación consiste en entregar al acreedor (en este caso al locatario) una suma de dinero que corresponda al valor adquisitivo que tenía la cantidad de dinero prevista al constituirse la obligación (Silvero Fernández, 2020).

Por otro lado, para el caso de existir alguna deuda por servicios públicos domiciliarios o expensas, correspondientes al período contractual y que al momento de la entrega del inmueble no hubiese sido facturada, el nuevo artículo 1196 brinda dos alternativas. Por un lado, puede acordarse su pago tomando al efecto los valores del último servicio o expensas abonado, o bien, como segunda alternativa, el locador puede retener una suma equivalente a dichos montos como garantía de pago. En este último caso, agrega el artículo, una vez que el locatario abone las facturas remanentes, debe presentar las constancias al locador, quien debe restituir de manera inmediata las sumas retenidas.

Por su parte, el inciso "c" se mantiene intacto en relación con la redacción original, estableciendo que no puede exigirse al locatario en una locación habitacional, el pago del valor llave o equivalentes.

Otra novedad, es la introducida por el inciso "d" del artículo analizado, que establece la prohibición de exigir al locatario habitacional, la firma de pagarés o cualquier otro documento que no forme parte del contrato original. 
De este modo, se trata de evitar que el locatario quede sometido a una doble deuda, porque ya el contrato es suficiente para el reclamo de los alquileres y otras consecuencias de la locación, por lo tanto, si se firman pagarés o cualquier otro documento, debe estar relacionado en el contrato, es decir, referido o mencionado expresamente en el mismo (Falcón, 2020).

\section{Artículo $3^{\circ}$ : Artículo 1198 CCC. Plazo mínimo de la loacación de inmueble}

El nuevo artículo 1198, en una redacción similar a la del texto aprobado en el año 2015, establece que el plazo mínimo legal del contrato de locación inmueble es de tres años, incrementando en un año el previsto por la redacción original, que establecía un mínimo de dos.

Asimismo, el artículo establece que, cualquiera sea el destino del contrato de locación de inmueble, si carece de plazo expreso y determinado mayor, se considera celebrado por el plazo mínimo legal, es decir, en los contratos que se celebren a partir del 01 de julio de 2020, por tres años, excepto aquellas excepciones contempladas en el artículo 1199 del CCC.

Por último, el párrafo segundo del artículo de referencia, establece que el locatario puede renunciar a este plazo si está en tenencia de la cosa, por lo que el mínimo obliga al locador y no al locatario. Este párrafo es de aplicación directa a los casos de renovación de contratos.

\section{Artículo $4^{\circ}$ : Artículo 1199 CCC - Excepciones al plazo mínimo legal}

Por su parte, el artículo 1199 del CCC determina las excepciones al plazo mínimo legal prescribiendo que el mismo no será de aplicación a los contratos de locación de inmuebles o parte de ellos destinados a:

a) Sede de embajada, consulado u organismo intermacional, y el destinado a habitación de su personal extranjero diplomático o consular;

b) Habitación con muebles que se arriende con fines de turismo, descanso o similares. Si el plazo del contrato o de los contratos consecutivos supera los tres (3) meses, se presume que no fue hecho con esos fines;

c) Guarda de cosas;

d) Exposición u oferta de cosas o servicios en un predioferial.

Tampoco se aplica el plazo mínimo legal a los contratos que tengan por objeto el cumplimiento de una finalidad determinada expresada en el contrato y que debe normalmente cumplirse en el plazo menor pactado.

La redacción es idéntica a la del CCC, solo sufriendo una variación en el inciso b en relación a los contratos de locación de inmuebles destinados a habitación con muebles con fines turísticos, descanso o similares. Para este caso, la norma original preveía la presunción de que no era hecho con esos fines cuando el contrato superara los tres meses, incluyendo el nuevo texto intro- 
ducido por la ley 27.551 también a aquellos supuestos en los que existen contratos consecutivos que superen el plazo máximo estipulado para ese tipo de contratación (de tres meses).

\section{Artículo $5^{\circ}$ : Artículo 1201 CCC. Conservar la cosa con aptitud para el uso convenido}

El artículo $5^{\circ}$ de la ley 27.551 reemplaza, asimismo, el artículo 1201 del CCC disponiendo, como en su redacción original, que el locador debe conservar la cosa locada en estado de servir al uso y goce convenido y efectuar a su cargo la reparación que exija el deterioro en su calidad o defecto, cuando este sea, dice la nueva redacción, originado por cualquier causa no imputable al locatario.

Se reemplaza de este modo, el texto aprobado en el año 2015, que disponía que debía efectuar a su cargo la reparación que exija el deterioro originado en su calidad o defecto, en su propia culpa, o en la de sus dependientes o en hechos de terceros o caso fortuito.

De este modo, se hace más extensa la responsabilidad de locador, hacia el caso fortuito y las causales mediatas e inmediatas, de manera que la única forma por la que se puede eximir de responsabilidad es cuando la calidad o defecto se deba a una causa imputable al locatario (Falcón, 2020).

Innova el artículo al disponer que, en caso de negativa o silencio del locador ante un reclamo del locatario para que efectúe alguna reparación urgente, este último puede realizarla por sí, una vez transcurridas al menos veinticuatro (24) horas corridas, contadas a partir de la recepción de la notificación. La reparación efectuada per se por el locatario, con arreglo al párrafo anterior, será a cargo del locador.

En caso de que las reparaciones no fueran urgentes, el locatario debe intimar al locador para que realice las mismas dentro de un plazo que no podrá ser inferior a diez días corridos, contados a partir de la recepción de la intimación. Cumplido el plazo otorgado, el locatario podrá efectuar la reparación por sí mismo, con cargo al locador.

La urgencia o no de las reparaciones es una cuestión que deberá ser analizada en cada caso en particular, y que suscitará numerosas controversias en la práctica, lo que deberá ser analizado a la luz de la cooperación debida entre las partes del contrato y el principio de buena fe que debe imperar en las relaciones jurídicas.

En estos casos tomará un rol preponderante el domicilio electrónico que, conforme los fundamentos del proyecto, tiene por fin 'brindar una opción de notificación más moderna, efectiva y de bajo costo... lo que permitirá además tener una mayor seguridad respecto a la recepción de las reclamaciones, minimizando la posibilidad de realizar acciones dilatorias...". Seguramente, la casuística nos indicará con el tiempo si se alcanzaron los fines propuestos.

En este sentido el artículo dispone que, para todos los casos la notificación remitida al domicilio denunciado por el locador en el contrato se tendrá por válida, aun si el locador se negara a recibirla o no pudiese perfeccionarse por motivos imputables al mismo. 
Se elimina, en la nueva redacción del artículo, el derecho del locatario a que se le reduzca el canon locativo temporariamente si al efectuar la reparación o innovación se interrumpe o turba el uso y goce convenido. La reducción prevista en el artículo reemplazado, debía considerarse en proporción a la gravedad de la turbación, otorgando incluso, el derecho al locatario a resolver el contrato en los casos más extremos. Más allá de la supresión efectuada en este artículo, idéntica posibilidad surge de la reforma introducida al artículo que a continuación analizaremos (1203), por lo que en la práctica el locatario no acarrearía con perjuicio alguno derivado de la presente modificación.

\section{Artículo $6^{\circ}$ : Artículo 1203 CCC. Frustración del uso y goce de la cosa}

El nuevo texto del artículo analizado establece que si por causas no imputables al locatario, éste se ve impedido de usar o gozar de la cosa, o ésta no puede servir para el objeto de la convención, puede pedir la rescisión del contrato, o la cesación del pago del precio por el tiempo que no pueda usar o gozar de la cosa.

La redacción es similar a la del CCC, reemplazando el "caso fortuito o fuerza mayor" de la redacción original, por "causas no imputables al locatario" en la nueva redacción, término que ya ha sido analizado en el artículo anterior.

Por su parte, el artículo mantiene la condición de que, si la cosa no se viese afectada directa o indirectamente, las obligaciones del locatario (y del locador) continúan como antes; es decir que el impedimento debe resultar grave y recaer sobre una prestación de carácter esencial.

\section{Artículo $7^{\circ}$ : Artículo 1.204 bis CCC. Compensación}

El artículo $7^{\circ}$ de la Ley 27.551 agrega como artículo 1204 bis del Código Civil y Comercial de la Nación, el referido a la compensación, disponiendo el artículo incorporado que los gastos y acreencias que se encuentran a cargo del locador conforme las disposiciones de la sección $4^{\mathrm{a}}$ del CCC -Efectos de la locación-, pueden ser compensados de pleno derecho por el locatario con los cánones locativos, requiriendo una previa notificación fehaciente al locador del detalle de los mismos.

De de la expresión "pueden ser compensados" surge que queda a elección del locatario realizar la compensación. Si este desea compensar, debe notificar en forma fehaciente y detallada al locador de los gastos en los que ha incurrido y que, conforme a la normativa, deben ser soportados por este último, de esta manera la compensación se producirá de pleno derecho (Rosas, 2020).

La autora citada en el párrafo precedente, afirma que se trata de un caso de compensación legal, por lo que procede aún ante la negativa del locador de autorizar la realización de las reparaciones al locatario. 


\section{Artículo $8^{\circ}$ : Artículo 1209 CCC. Pagar cargas y contribuciones por la actividad}

El nuevo artículo 1209, sustituido por la Ley en análisis, mantiene a cargo del locatario las cargas y contribuciones que se originen en el destino que dé a la cosa locada.

Por su parte, el artículo estipula expresamente que el locatario no tiene a su cargo el pago de las cargas y contribuciones que graven la cosa. Si bien la redacción del CCC ya lo contemplaba, otorgaba la posibilidad a las partes de pactar en contrario, facultad que no otorga el nuevo artículo, por lo que estamos frente a una cláusula de orden público, puesta en protección del locatario.

Asimismo, la nueva redacción establece que tampoco estarán a cargo del locataio las expensas comunes extraordinarias. Estas derivan de aquellos gastos que debe efectuar el consorcio de copropietarios, pero tienen el carácter de extraordinarias porque se fijan por disposición de la asamblea a fin de solventar gastos que no son ordinarios o de administración (Malizia, 2015). Estas expensas, conforme el artículo 2048 del CCC, ya se encontraban a cargo del propietario.

Por último, agrega el artículo, que solo puede establecerse que estén a cargo del locatario aquellas expensas que deriven de gastos habituales, entendiéndose por tales aquellos que se vinculan a los servicios normales y permanentes a disposición del locatario, independientemente de que sean considerados como expensas comunes ordinarias o extraordinarias, siendo este enunciado incorporado por la Ley 27.551.

\section{Artículo 9º : Artículo 1221 CCC. Resolución anticipada}

El artículo $9^{\circ}$ de la ley 27.551 viene a sustituir el artículo 1221 del CCC disponiendo que el contrato de locación puede ser resuelto anticipadamente por el locatario; en primer término, si la cosa locada es un inmueble y han transcurrido seis meses de contrato, debiendo notificar en forma fehaciente su decisión al locador con al menos un mes de anticipación. Si hace uso de la opción resolutoria en el primer año de vigencia de la relación locativa debe abonar al locador, en concepto de indemnización, la suma equivalente a un mes y medio de alquiler al momento de desocupar el inmueble y la de un mes si la opción se ejercita transcurrido dicho lapso.

En este primer supuesto, se incorpora la obligación del locatario de notificar su decisión al locador con al menos un mes de anticipación, lo que no era previsto por el texto original del CCC, que solo preveía el deber de notificar fehacientemente, pero sin estipular un plazo determinado.

Sin embargo, la novedad de mayor transcendencia que trae el artículo se encuentra en el párrafo segundo del inciso "a" al disponer que, en los contratos de inmuebles destinados a vivienda, cuando la notificación al locador se realiza con una anticipación de tres meses o más, transcurridos al menos seis meses de contrato, no corresponde el pago de indemnización alguna por dicho concepto. 
Puede leerse en los fundamentos del proyecto legislativo que, para la modificación señalada en párrafo precedente, se ha tenido en cuenta "la razonabilidad del plazo establecido a los fines de que el locador adopte los recaudos pertinentes".

En cuanto al inciso b del artículo, se mantuvo idéntico a la redacción original, estableciendo que en los casos del artículo 1199 analizado previamente (excepciones al mínimo legal), el contrato de locación puede ser resuelto anticipadamente por el locatario debiendo abonar al locador el equivalente a dos meses de alquiler. Cabe resaltar que esta opción está puesta solo en cabeza del locatario, y en ningún caso está autorizada al locador.

\section{Artículo 10: Artículo 1221 bis CCC. Renovación del contarto}

Otra de las importantes novedades de la ley 27.551, es la introducida por su artículo 10, al incorporar al CCC como artículo 1221 bis, lo ateniente a un procedimiento anticipado de renovación del contrato de locación del inmueble destinado a vivienda.

Establece el artículo que en estos contratos (destinado a vivienda), dentro de los tres últimos meses de la relación locativa, cualquiera de las partes (locador o locatario) puede convocar a la otra -notificándola en forma fehaciente- a efectos de acordar la renovación del contrato en un plazo no mayor a quince días corridos.

En caso de darse la convocatoria por parte de locatario y ante el silencio del locador o frente a la negativa de este llegar a un acuerdo, estando debidamente notificado, el locatario puede resolver el contrato de manera anticipada sin pagar la indemnización correspondiente.

Es decir, el locatario podrá rescindir anticipadamente el contrato con destino habitacional sin abonar la indemnización al locador si no concretan el acuerdo de prórroga, si el locador se niega a sentarse a renegociar la continuidad de la relación locativa o si hace caso omiso a la notificación cursada por el locatario (Silvero Fernández, 2020).

Analizado el presente artículo, Quaglia (2020) sostiene que la exigencia de la renovación o renegociación a través de una norma no puede sino plantearse como una obligación de medios, a fin de no violar el principio de la libertad de contratar. Razón por la cual, la imposición de una eventual sanción al locador en forma incausada, consistente en la posibilidad de resolución anticipada sin pago de indemnización, no termina de convencer, a diferencia del caso de silencio o renuencia a renovar el contrato en forma injustificada.

\section{Artículo 11: Artículo 1222 CCC. Intimación de pago y desalojo de vivienda}

El primer párrafo del artículo 1222, es idéntico a la redacción original del artículo en el CCC, que fuera reemplazado por la ley en análisis. Establece que, si el destino es habitacional, previamente a la demanda de desalojo por falta de pago de alquileres, el locador debe intimar 
fehacientemente al locatario al pago de la cantidad debida, otorgando para ello un plazo que nunca debe ser inferior a diez días corridos contados a partir de la recepción de la intimación y especificando el lugar de pago.

Esta intimación previa deberá ser efectuada en el domicilio denunciado por el locatario, pudiendo dirigírsela también al domicilio electrónico, si las partes lo han previsto.

De modo que existe una sola diferencia; el CCC establecía que debía "consignarse" el lugar de pago, mientras que la nueva redacción determina que debe "especificarse", lo que más allá de una cuestión terminológica, no parecería tener una implicancia práctica.

Sin embargo, los cambios en el artículo aparecen a partir de su segundo párrafo, que aclara que la notificación remitida al domicilio denunciado en el contrato por el locatario se tiene por válida, aun si éste se negara a recibirla o no pudiese perfeccionarse por motivos imputables al mismo.

Por su parte, el párrafo tercero dispone que cumplido el plazo otorgado por el locador para el pago de los alquileres debidos sin que estos sean abonados, o habiéndose verificado la extinción de la locación por cualquier motivo, el locatario debe restituir la tenencia del inmueble locado al locador.

Ante el incumplimiento del locatario de lo estipulado en el párrafo precedente, el artículo determina que el locador puede iniciar la acción judicial de desalojo, que debe sustanciarse por el proceso previsto al efecto en cada jurisdicción y, en caso de no prever un procedimiento especial, el más abreviado que establezcan sus leyes procesales o especiales.

Por otro lado, el párrafo cuarto incorporado por la normativa analizada, dispone que en ningún caso el locador puede negarse a recibir las llaves del inmueble o condicionar la recepción de las mismas, más allá de reservarse los créditos pendientes frente al locatario.

En caso de negativa o silencio del locador frente al requerimiento del locatario de que reciba las llaves del inmueble, éste último podrá realizar la consignación judicial de las mismas, siendo los gastos y costas a cargo del locador.

Por último, establece el artículo que en ningún caso se adeudarán alquileres ni ningún tipo de obligación accesoria a partir del día de la notificación fehaciente dirigida al locador, siempre que el locatario efectúe la consignación judicial de las llaves del inmueble dentro de los diez días hábiles siguientes a la notificación. Evidentemente, esta medida posee un claro afán disuasorio para el locador, al negarle la posibilidad de percibir alquileres por el plazo que transcurra en la dilucidación de cuestiones en que no haya coincidencias; máxime en épocas inflacionarias.

En cambio, si la consignación judicial se hubiese iniciado una vez vencido el plazo de diez días hábiles a partir de la notificación fehaciente, no se adeudarán alquileres ni ningún un tipo de obligación accesoria, a partir de que le fuera notificado al locador el depósito judicial de la llave. 


\section{Artículo 12: Artículo 1351 CCC. Intervención de uno o varios corredores}

El artículo 12 es la última modificación que hace la ley 27.551 al CCC, sustituyendo el artículo 1351 de ese cuerpo normativo en lo que refiere a la intervención de los corredores.

El primer párrafo del artículo se mantiene intacto al establecer que, si solo interviene un corredor, todas las partes le deben comisión, excepto pacto en contrario o protesta de una de las partes según el artículo 1346. No existe solidaridad entre las partes respecto del corredor. Si interviene un corredor por cada parte, cada uno de ellos solo tiene derecho a cobrar comisión de su respectivo comitente.

Sin embargo, la novedad está dada por el párrafo segundo del nuevo artículo 1351, al disponer que en las locaciones de inmuebles la intermediación solo podrá estar a cargo de un profesional matriculado para ejercer el corretaje inmobiliario, entrando en juego la legislación local (provincial) al respecto.

Desde luego que las partes, de conformidad al principio de autonomía de la voluntad, podrán celebrar un contrato sin la participación o intervención de un corredor, debido a que la actuación de ese profesional, implica erogación monetaria extra tanto para el locatario como para el locador.

\section{TÍTULO II. REGULACIÓN COMPLEMENTARIA DE LAS LOCACIONES}

Los artículos que comprenden el título II de la Ley 27.551 (artículos 13 a 16) no introducen una modificación al Código Civil y Comercial de la Nación, sino que constituyen normativa complementaria, constituyendo, así, una suerte de descodificación de la materia.

Es importante señalar la opinión de Hernández (2020), al manifestar que se ha retornado a un estadio de "descodificación", aunque diferente a la de otros tiempos, siendo el propósito acotado o parcial. Aclara el autor que en el cuerpo del CCC sigue concentrándose el núcleo de toda la regulación de las locaciones, argumentando que la "descodificación" apunta en menor medida a temas contractuales, poniendo énfasis en las cuestiones tributarias, administrativas y procesales.

\section{Artículo 13. Garantía}

El artículo 13 de la Ley 27.551 establece que en las locaciones habitacionales, en el caso de requerirse una garantía, el locatario debe proponer al locador al menos dos de las enumeradas entre los incisos "a" y "e" del mismo artículo. Estas son: título de propiedad inmueble, aval bancario, seguro de caución, garantía de fianza o fiador solidario o garantía personal del locatario. 
La última de las enumeradas, dice la ley, se documenta con recibo de sueldo, certificado de ingresos o cualquier otro medio fehaciente, debiendo, en caso de ser más de un locatario, sumarse los ingresos de cada uno de ellos. Realmente, esto constituye una acreditación de solvencia del futuro locatario y no, precisamente, una garantía.

En su párrafo tercero, el artículo analizado, dispone que el locador no puede requerir una garantía que supere el equivalente a cinco veces el valor mensual de la locación, salvo que se trate de una garantía personal del locatario, en cuyo caso puede elevarse dicho valor hasta un máximo de diez veces. Efectuado el ofrecimiento por parte del locatario, el locador debe aceptar una de las garantías propuestas; es decir que no constituye una facultad para él.

Por último, la ley deja en manos de una futura reglamentación la regulación de los requisitos que debe cumplir quien desea otorgar aval bancario, seguro de caución o garantía de fianza, o comprometerse como fiador solidario, así como las características y condiciones de cada una de estas garantías. En atención a esta futura reglamentación Hernández (2020) afirma que estamos frente a una norma incompleta que -al menos en gran medida- no parece operativa.

\section{Artículo 14. Ajustes}

El artículo de referencia dispone que los contratos de locación, independientemente cual sea su destino, están exceptuados de lo dispuesto en los artículos 7 y 10 de la ley de convertibilidad del Austral (Ley 23.928) y sus modificatorias.

Puede leerse en los fundamentos del proyecto legislativo que "uno de los aspectos que mayor inseguridad general genera a ambas partes en la relación locativa es sin duda la prohibición de indexación estatuida mediante los artículos $7^{a}$ y 10 de la Ley de Convertibilidad del Austral $N^{\circ}$ 23.928, sancionada en el año 1991 y sus modificatorias, en virtud de que la imposibilidad de generar ajustes generó mecanismos de actualización basado en perspectivas, muchas veces subjetivas, relacionadas con la inflación futura... ocasionando diferencias a favor de una u otra parte según el periodo que se analice".

Más allá de la excepción introducida, la ley 27.551 incorpora una limitación al establecer que, en los contratos de locación de inmuebles destinados a uso habitacional, el precio del alquiler debe fijarse como valor único y por períodos mensuales, sobre el cual solo pueden realizarse ajustes anuales. Estos ajustes a su vez, deberán efectuarse utilizando un índice que será elaborado y publicado mensualmente por el Banco Central de la República Argentina, el que estará conformado por partes iguales por las variaciones mensuales del índice de precios al consumidor (IPC) y la remuneración imponible promedio de los trabajadores estables (RIPTE).

Asimismo, agrega el artículo que en ningún caso pueden establecerse bonificaciones ni otras metodologías que induzcan a error al locatario, demostrando la clara intención tuitiva de la ley. 
Cabe destacar, que la reforma es válida para todos los destinos en lo referente a la excepción al régimen instaurado por los artículos $7^{\circ}$ y 10 de la ley de convertibilidad, aunque en el campo habitacional impone la utilización de índices mixtos establecidos por el Estado, a fin de evitar incrementos excesivos que comprometan la capacidad de pago del locatario en tiempos de alta inflación. En tal sentido es importante remarcar que en los destinos no habitacionales no resulta una alternativa obligatoria, quedando abierta la posibilidad de emplear mecanismos de determinación del precio y cláusulas de escalonamiento (Hernández \& Frustagli, 2020).

\section{Artículo 15. Consignación}

Por su parte, el artículo 15 de la ley 27.551 regula el caso de negativa al cobro del alquiler por parte del locador, no haciendo alusión a si la misma debe o no ser injustificada, por lo que parecería hacer referencia a todo tipo de negativa. En tal sentido, el artículo dispone que, si el locador se rehusare a cobrar el canon locativo, el locatario debe intimarlo de manera fehaciente a que lo reciba dentro de las cuarenta y ocho horas siguientes a su notificación.

En caso de silencio ante la notificación o negativa del locador a recibirlo, el locatario, dentro de los tres días hábiles siguientes al vencimiento del plazo estipulado en la notificación, debe proceder a la consignación judicial del monto adeudado.

Si bien el artículo 910 del CCC prevé la posibilidad de consignación extrajudicial ante un escribano de registro, como opción para el deudor de una suma de dinero, el artículo 15 de la ley 27.551 solo estipula para los casos de negativa al cobro del alquiler por parte del locador la consignación judicial.

El artículo brinda como otra alternativa al locatario, la posibilidad de efectuar el pago mediante cheque cancelatorio, estando los gastos y costas correspondientes a cargo del locador.

\section{Artículo 16. Declaración ante la Administración Federal de Ingresos Públicos (AFIP)}

El artículo en análisis establece que los contratos de locación de inmueble deben ser declarados por el locador ante la Administración Federal de Ingresos Públicos de la Nación (AFIP), dentro del plazo, en la forma y con los alcances que dicho organismo disponga.

Por su parte el organismo debe disponer un régimen de facilidades para la registración de contratos vigentes. El incumplimiento del locador lo hace pasible de las sanciones previstas en la ley de procedimientos fiscales (Ley 11.683).

Agrega el párrafo segundo del artículo que cuando se inicien acciones judiciales a causa de la ejecución de un contrato de locación, previo a correr traslado de la demanda, el juez debe informar a la Administración Federal de Ingresos Públicos de la Nación (AFIP) sobre la existencia del contrato, a los fines de que tome la intervención que co- 
rresponda. Además, la ley analizada pone la facultad de informar también en cabeza del locatario, al establecer que, sin perjuicio de la obligación del locador, cualquiera de las partes puede informar la existencia del contrato a la Administración Federal de Ingresos Públicos de la Nación (AFIP).

La notificación tiene un carácter impositivo, a los fines del control y recaudación por parte del Estado y, en su caso, en miras a la aplicación de las sanciones reguladas en las normas tributarias ante los casos de incumplimiento.

Cabe preguntarnos si como lo establece el artículo, la comunicación solo debe darse en los casos en los cuales se ejecuten alquileres, dejando así afuera los procesos de desalojos y otras controversias que se susciten en los estrados judiciales. Más allá que la norma así no lo indica así, hay autores que consideran que debe incluirse todo tipo de proceso jurisdiccional en los que se involucre un contrato de locación (Pano \& Salgado, 2020).

\section{TÍTULO III: PROGRAMA NACIONAL DE ALQUILER SOCIAL}

El título III de la ley en estudio se denomina Programa Nacional de Alquiler Social, regulado entre los artículos 17 y 20 de este cuerpo normativo.

Justamente, el artículo 17 crea el programa mencionado, el que estará destinado a la adopción de medidas que tiendan a facilitar el acceso a una vivienda digna en alquiler mediante una contratación formal, conforme lo dispone el referido artículo. Programa que, a su vez, tendrá como organismo rector al Ministerio del Interior, Obras Públicas y Vivienda, a través de la Secretaría de Vivienda, quien tendrá a su cargo el diseño de las políticas públicas destinadas a efectivizar los fines propuestos.

Por su parte, el artículo 19 enumera las medidas de implementación del programa, las que constituyen interesantes declaraciones en favor de los sectores más vulnerables. Sin embargo, a los fines de ser efectivizadas, deberán contemplar los diversos aspectos relacionados, como ser la posibilidad de afrontar responsablemente los compromisos de pago del canon locativo comprometido, siendo este uno de los elementos determinantes del tipo contractual analizado.

\section{TÍTULO IV: MÉTODOS ALTERNATIVOS DE RESOLUCIÓN DE CONFLICTOS}

La Ley encomienda al Poder Ejecutivo nacional, a través del Ministerio de Justicia y Derechos Humanos, que junto a las provincias y la Ciudad Autónoma de Buenos Aires, fomenten 
el desarrollo de ámbitos de mediación y arbitraje, gratuitos o de bajo costo, aplicando métodos específicos para la resolución de conflictos derivados de la relación locativa.

Por su parte se sustituye el artículo $6^{\mathbf{0}}$ de la ley 26.589, que disponía que en los casos de ejecución y desalojos el procedimiento de mediación prejudicial obligatoria será optativo para el reclamante sin que el requerido pueda cuestionar la vía.

La ley analizada viene a modificar el texto original de esta Ley de Mediación y Conciliación, eliminando del artículo $6^{\circ}$ el carácter optativo de la mediación prejudicial, siendo, a partir de la modificación, una instancia obligatoria para los casos de desalojos en el ámbito federal.

\section{Art. 23. Entrada en vigencia de la ley 27.551}

El artículo analizado dispone que la ley entrará en vigencia el día siguiente al de su publicación en el Boletín Oficial y será aplicable para los contratos que se celebren a partir que la misma entre en vigor.

La ley fue publicada el día 30 de junio de 2020, por lo que entró en vigencia el día 1 de julio de 2020, siendo la misma aplicable consecuentemente a los contratos celebrados a partir de ese día.

El debate se suscita respecto de los contratos de locación que constituyen un contrato de consumo; estos son, según Moeremans (2015) los casos en los que el locatario es un consumidor en la terminología del Código, es decir, celebra el contrato para beneficio propio o de su grupo familiar o social mientras que el locador es un proveedor profesional de bienes y servicios. En tales casos la normativa aprobada, en cuanto constituya una norma más favorable al consumidor, es de aplicación inmediata a los contratos en curso de ejecución.

En este sentido se expresan Herrera \& Caramelo (2015) sosteniendo que las leyes de protección de los consumidores, sean supletorias o imperativas, son de aplicación inmediata, teniendo la norma una clara raigambre constitucional y estando la misma estructurada sobre la base de una razonable aplicación del principio protectorio propio del derecho del consumo.

\section{NORMATIVA DE EMERGENCIA}

Antes de finalizar resulta menester señalar que está vigente en nuestro país, el Decreto de Necesidad y Urgencia $\mathrm{N}^{\circ} 766 / 20$ que prorroga las medidas adoptadas por el Decreto 320/20, esto es, congela el precio de los alquileres, prórroga los contratos y suspende los desalojos hasta el 31 de enero de 2021. 
Si bien el análisis de la normativa excede el objeto del presente trabajo, no puede dejar de señalarse que a través del mencionado Decreto se dispone la prórroga de la vigencia, hasta el día 31 de enero de 2021, de los contratos de locación de inmueble cuyo vencimiento opere entre el 20 de marzo de 2020 y el 31 de enero de 2021.

Ello siempre y cuando el inmueble sea uno de los individualizados en el artículo $9^{\circ}$ del Decreto 320/20 y la tenencia del mismo se encuentre en poder de la parte locataria, sus continuadores o continuadoras, sus sucesores o sucesoras por causa de muerte, o de un sublocatario o una sublocataria, si hubiere.

Es decir que, ante el vencimiento, la parte locataria podrá optar por mantener la fecha pactada por las partes, prorrogar el vencimiento hasta el 31 de enero de 2021, o prorrogar dicho plazo por un término menor al autorizado por los Decretos.

Lo expuesto lleva a que deba analizarse cada caso en concreto a la luz del CCC, del DNU 320/20 y su prórroga, DNU 766/20, y de la Ley 27.551, constituyendo un plexo normativo complejo, el cual los operadores del Derecho deberán articular en consideración a las circunstancias de hecho y en el marco del diálogo de fuentes dispuesto por el Código Civil y Comercial.

\section{CONCLUSIÓN}

Como se ha dicho, en materia contractual rige el principio de autonomía de la voluntad y de libertad de contratación, que otorga a las partes la posibilidad de celebrar un contrato y determinar su contenido, siempre que con esto no se contraríe la ley, el orden público, la moral y las buenas costumbres. En este orden, las normas relativas a los contratos son, en principio, supletorias de la voluntad de las partes, tomando esto un especial valor en los contratos paritarios o negociados.

Sin embargo, en materia locativa, hay una notable tendencia legislativa de incrementar la protección al locatario en desmedro del locador, por ser el primero la parte débil de la relación jurídica. Esta tendencia no adquiere operatividad sino a través de normas de orden público de protección, que excluyen la posibilidad de las partes de pactar en contrario, aún en los casos en que las mismas se encuentren en igualdad de condiciones y conozcan las ventajas y desventajas que puedan derivar del negocio jurídico a celebrar.

La ley 27.551 que entró en vigor el $1^{\circ}$ de julio y que es, en principio, aplicable a los contratos de locación celebrados a partir de ese día, no escapa de esta corriente legislativa tuitiva, planteando un renovado esquema de derechos y obligaciones para las partes del contrato de locación.

Si bien las novedades incorporadas, como ser el incremento del plazo mínimo de locación, el índice para la actualización anual de los precios, la posibilidad de constituir un domici- 
lio electrónico, la obligación de declarar el contrato ante la Administración Federal de Ingresos Públicos de la Nación (AFIP), entre muchas otras; son en su esencia loables, solo el tiempo nos demostrará si han cumplido con los fines propuestos, o bien, como lo dejan entrever algunos artículos periodísticos, tendrán el impacto contrario al deseado, como ser aumentos de los precios de mercado o un incremento de la clandestinidad en las relaciones locativas, a los fines de evitar la aplicación de las "nuevas reglas".

Por último, como se ha señalado, si bien la ley no ha tenido una incidencia directa en la normativa de emergencia en materia locativa, requiere su articulación por parte de los operadores del derecho para determinar cuál será en cada caso la normativa aplicable, en el marco del diálogo de fuentes propuesto por el CCC.

\section{REFERENCLAS BIBLIOGRÁFICAS}

Ayala, M. (2020). Autonomía de la Voluntad y Ley de Alquileres. En Lezcano J.M. \& Krieger W.F. (Directores) Locaciones Urbanas. Análisis de las Modificaciones de la Nueva Ley de Alquileres. Buenos Aires, Argentina: IJ Editores. Cita: IJ-CMXXIII-11.

Di Chiazza, I. (2016). En Rivera, J. y Medina G. (Directores). Contratos Parte Especial. Ciudad Autónoma de Buenos Aires, Argentina: Abeledo Perrot.

Falcón, E. (2020). Comentario a las reformas al Código Civil y Comercial en materia de locaciones y otras disposiciones - Ley 27551. Santa Fe, Argentina: Rubinzal Culzoni. Cita: RC D $2820 / 2020$.

Hernández, C. \& Frustagli, S. (2017). En Nicolau, N. \& Hernández C. (Directores). Contratos en el Código Civil y Comercial de la Nación. Ciudad Autónoma de Buenos Aires, Argentina: La Ley.

Hernández, C. (2020). Reforma a las locaciones: el impacto de la Ley 27551. Santa Fe, Argentina: Rubinzal Culzoni. Cita: RC D 2862/2020.

Hernández, C. y Frustagli, S. (2020). Reforma a las locaciones: el impacto de la Ley 27551. Santa Fe, Argentina: Rubinzal Culzoni. Cita: RC D 2890/2020. 
Herrera, M. \& Caramelo, G. (2015). Comentario del Título Preliminar. En Herrera, M., Caramelo, G. \& Picasso, S. (Directores). Código Civil y Comercial de la Nación Comentado. Ciudad Autónoma de Buenos Aires, Argentina: Infojus.

Krieger, W. (2018). Contrato de Locación conceptos y elementos. En Borda, A. Derecho Civily Comercial, Contratos. Ciudad Autónoma de Buenos Aires, Argentina: La Ley.

Malizia, R. (2015). Comentario al Título V. Propiedad Horizontal. En Herrera, M., Caramelo, G. \& Picasso, S. (Directores). Código Civil y Comercial de la Nación Comentado. Ciudad Autónoma de Buenos Aires, Argentina: Infojus.

Moeremans, D. (2015). Locación. En Lorenzetti, R. L. (Director) Código Civil y Comercial de la Nación Comentado. Santa Fe, Argentina: Rubinzal Culzoni.

Moroz, R. F. (2020). El Domicilio Especial Electrónico. En Lezcano J.M \& Krieger W.F. (Directores) Locaciones Urbanas. Análisis de las Modificaciones de la Nueva Ley de Alquileres. Buenos Aires, Argentina: IJ Editores. Cita: IJ-CMXXIII-31.

Pano, S. \& Salgado, J. (2020). Novedades en las relaciones locativas de inmuebles urbanos. Santa Fe, Argentina: Rubinzal Culzoni. Cita: RC D 2816/2020.

Rosas, C. (2020). Régimen de reparaciones y compensación en la nueva normativa de Locaciones. En Lezcano J.M \& Krieger W.F. (Directores) Locaciones Urbanas. Análisis de las Modificaciones de la Nueva Ley de Alquileres. Buenos Aires, Argentina: IJ Editores. Cita: IJ-CMXXIII-41.

Silvero Fernandez, C. (2020). Nueva Ley de Alquileres: comentarios a la ley 27551. Resistencia, Argentina: Contexto Libros.

\section{CURRICULUM VITAE}

\section{Federico Manuel Lértora}

Abogado y Profesor Universitario (UNNE). Auxiliar Docente de Primera de las Cátedras Fundamentos de Derecho Civil y Comercial y Derecho de Contratos y Títulos Valores de la Facultad de Ciencias Económicas de la Universidad Nacional del Nordeste, Argentina. federicolertora@hotmail.com 